\section{A Cidade Olímpica de Piraju (SP) - Interface entre o Jornalismo Esportivo, o Meio Ambiente e a Canoagem*}

The Olimpic City Of Piraju (SP) - Interface between Sports Journalism, Environment and Canoeing

\section{RESUMO}

Este artigo revela a experiência do projeto A Cidade Olímpica de Piraju (SP) - Interface entre o Jornalismo Esportivo, o Meio Ambiente e a Canoagem, que foi desenvolvido na Universidade de São Paulo entre 2012 e 2013. A iniciativa foi premiada em primeiro lugar na área de Ciências Humanas do $3^{\circ}$ Simpósio Aprender com Cultura e Extensão, promovido pela Pró-Reitoria de Cultura e Extensão Universitária da USP, em 2013. O contato com a natureza e os moradores locais foram determinantes para a inserção da bolsista diante da proposta. Além disso, a iniciativa propiciou a integração entre a aluna, o coordenador (docente), os funcionários e os protagonistas, eixo fundamental para o desenvolvimento de projetos de ensino, pesquisa, cultura e extensão em universidades. O projeto segue o ideal do curso de graduação em Comunicação Social, com habilitação em Jornalismo, da ECA-USP, que é determinado pelo princípio da Universidade Aberta, estabelecendo um papel inovador ao oferecer serviços gratuitos à comunidade.

Palavras-chave: Canoagem. Estância Turística de Piraju. Meio Ambiente.Jornalismo.
LUCIANO Victor Barros MaLuLY

Universidade de São Paulo. Escola de Comunicações e Artes, São Paulo, Brasil

\begin{abstract}
This article reveals the experience of the project The Olimpic City of Piraju (SP) - Interface between Sports Journalism, Environment and Canoeing, which was developed in the University of Sao Paulo between the years 2012 and 2013. The initiative won the first place award in the field of Human Sciences during the 3 rd Symposium Aprender com Cultura e Extensão (free translation To Learn with Culture and University Extension), held by the Office of the Provost for Culture and Extension, in 2013. The
\end{abstract}

*Projeto vencedor na área de Ciências Humanas do $3^{\circ}$ Simpósio Aprender com Cultura e Extensão da Pró-Reitoria de Cultura e Extensão Universitária da USP em 2013. 
contact with nature and the local dwellers were decisive for the immersion of the student (scholarship recipient) in the proposal. Furthermore, the initiative propitiated the integration between the student, the coordinator (teacher), the personnel and the protagonists, which is a fundamental part to develop projects in education, research, culture and extension in Universities. The project follows the ideal of the Graduation Course in Social Communication, with emphasis in Journalism, from ECA-USP, which is determined by the principle of Open University, establishing an innovative role by offering free of charge services to the community.

Keywords: Canoeing. Touristic Ranch of Piraju. Environment. Journalism.

\title{
INTRODUÇÃO
}

\author{
ÁGUA BOA (essa cidade é o cais...) \\ Cidade onde a água faz curva \\ A curva do rio \\ A rua na margem \\ A margem do rio \\ A lua no meio \\ Do meio do rio \\ O rio corrente \\ $\mathrm{O}$ rio corrente \\ A água passando \\ O tempo batendo \\ A água levando \\ A água lavando \\ Mil peixes, mil copos \\ A água faz curvas \\ Além, muito além dessa curva \\ E vai... \\ Rio que não é reto, é denso \\ Rio que ponte abaixo tem garganta \\ Rio que pouco acima faz lagoa \\ Rio de água boa \\ Cidade na margem \\ $\mathrm{O}$ mar fica longe \\ $\mathrm{O}$ sol fica aqui \\ Paranapanema verde \\ Rio que vem lá da Usina \\ Águas descendo, descendo, descendo \\ Essa cidade é o cais... \\ [14]
}


"Passar a infância no interior" é uma experiência fantástica, em especial, pelo contado com a natureza, os amigos e parentes. Ficam as lembranças das peripécias e dos momentos felizes, como aqueles vividos com os pais e avós. A Estância Turística de Piraju, no interior de São Paulo, a 340 quilômetros da capital, é um desses lugares inesquecíveis. É ali onde fui criado num ambiente saudável, cheio de alegrias e descobertas, com destaque para o contato com o rio Paranapanema, local propício para o lazer e à prática dos esportes aquáticos. A natação, a pesca e os barcos constituíram esse cenário, que ainda permanece intacto em decorrência da luta dos ambientalistas locais.

Sempre comento na Universidade de São Paulo sobre esse tempo e, quando possível, toco a música Brasilinha, uma das faixas do CD São Sebastião do Tijuco Preto (referência ao antigo nome da cidade), do cantor, compositor e conterrâneo Oswaldinho Viana. Nela, uma frase resume um tempo de felicidade: Saudade é o tempo que ficou sem querer me abandonar [13].

Foi assim, depois de 25 anos vivendo fora do município, que recebi uma ligação telefônica de um amigo de infância, o Prof. Dr. José Luiz Fernandes Cerveira Filho, da Universidade Federal do Paraná. "Precisamos fazer um projeto sobre a nossa cidade", dizia. Escrevemos o artigo Comunicação, Esporte, Turismo e Meio Ambiente: Como a Canoagem Transformou Piraju (SP) em Cidade Olímpica, publicado na Revista Organicom (Número 15) da Escola de Comunicações e Artes (ECA-USP), no segundo semestre de 2011. O texto destaca a experiência dessa modalidade esportiva no município, com detalhes sobre a revelação de atletas olímpicos e a popularização do esporte e da atividade física. Os frutos desse trabalho são notórios, como é o caso da atleta Poliana Aparecida de Paula, ex-aluna da zona rural que foi a primeira brasileira a participar de uma Olimpíada, em Pequim (China), 2008, quando também alcançou um resultado inédito para o País ao chegar às semifinais da canoagem Slalom K1.

Uma das vertentes desse artigo foi a inscrição do projeto A Cidade Olímpica de Piraju (SP): Interface entre o Jornalismo Esportivo, o Meio Ambiente e a Canoagem no programa Aprender com Cultura e Extensão, edição 2012-2013, da Pró-Reitoria de Cultura e Extensão Universitária (PRCEU-USP). O eixo do trabalho seria a condução do jornalismo e, por conseguinte, do esporte como ferramenta de conscientização ambiental. Foi assim que recebi a bolsista Izabela de Souza Gusmão, do curso de bacharelado em Esporte da Escola de Educação Física e Esporte (EEFE-USP).

A primeira lição foi a de introduzir os valores do esporte e do olimpismo, como o respeito, a amizade e a excelência [3], revelando um universo maior que o da competitividade sem limites, sempre exaltada pela mídia.

Logo depois, possibilitou-se o contato com as ferramentas jornalísticas, fundamentadas pela discussão em torno da mensagem (técnica e conteúdo). $\mathrm{O}$ auxílio do funcionário Ulisses Rodrigues de Paula, do Departamento de Jornalismo e Editoração, foi fundamental naquele período, por possibilitar a inserção da aluna no universo digital, espaço ideal e barato para a divulgação do material impresso e em audiovisual. O trabalho atingiu ali um momento especial, pela integração da comunidade uspiana (aluno, professor e funcionário), parceira indispensável para a viabilização de projetos acadêmicos na Universidade, com a população, no caso os protagonistas (atletas, treinadores e demais integrantes). 
A etapa seguinte caracterizou-se pelo contato da aluna com o universo do esporte, no caso o da canoagem, fato propiciado com o apoio da Prefeitura Municipal da Estância Turística de Piraju (SP). Neste contexto, foi determinante o auxílio dos servidores públicos locais, que deram todo o respaldo à proposta. Com o fomento da Comissão de Cultura e Extensão da ECA, Izabela esteve no município. Para ela, seria a oportunidade de observar a relação entre o meio ambiente e o esporte na cidade em que uma modalidade olímpica depende da preservação de seu rio.

No mesmo espaço, que serve tanto à prática da canoagem como ao lazer dos moradores, Izabela conviveu com os atletas, que também ensinam aos cidadãos, especialmente às crianças, as técnicas da canoagem. Foi recebida com carinho e conheceu o trabalho realizado em Piraju e, assim, a realidade do esporte no Brasil, que sobrevive entre dificuldades e conquistas. Senti que o objetivo do projeto estava cumprido, pelo fato de demonstrar que "foi possível compartilhar o conhecimento e a felicidade", ensinamento deixado pela minha mãe, a educadora Maria Aparecida Barros Maluly.

No dia 10 de setembro de 2013, acordei às $3 \mathrm{~h}_{3} \mathrm{o}$ da madrugada para acompanhar Izabela e as demais bolsistas da ECA no $3^{\circ}$ Simpósio Aprender com Cultura e Extensão, evento que reúne cerca de mil projetos desenvolvidos na USP, realizado em Ribeirão Preto. Fomos muito bem recebidos pela equipe coordenada pelo Prof. Dr. José Nicolau Gregorin Filho. Após as palestras, as apresentações e as avaliações dos painéis, tivemos de retornar a São Paulo, porque todos estavam cansados e algumas alunas ainda teriam atividades na USP.

No meio do caminho, recebemos uma ligação do professor Dennis de Oliveira, da ECA, informando sobre a premiação do nosso projeto, com o primeiro lugar na área de Ciências Humanas. Fiquei muito emocionado, principalmente pelo dever cumprido e por perceber que a humildade e o cuidado com a formação dos nossos jovens são valores que continuam presentes nas escolas, como este exemplo da Universidade de São Paulo.

\title{
A PROPOSTA
}

\section{EXTENSÃO}

\author{
Eu busquei encontrar na extensão um caminho \\ Um caminho qualquer para qualquer lugar. \\ Eu segui ao sabor de todos os ventos \\ Mas somente a extensão. \\ Chorei. Prostrado na terra eu olhei para o céu \\ E pedi ao Senhor o caminho da fé. \\ Noites e noites foram-se em silêncio \\ E somente a extensão.
}




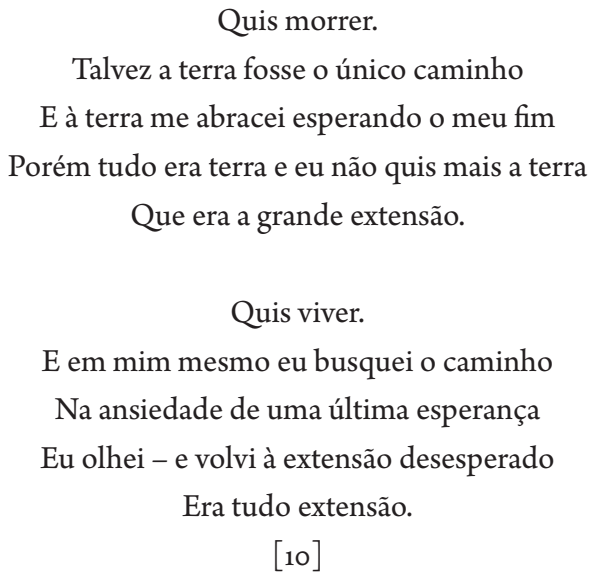

Na sequência, um resumo do projeto A Cidade Olímpica de Piraju (SP) - Interface entre o Jornalismo Esportivo, o Meio Ambiente e a Canoagem, que foi apresentado (em banner) pela aluna Izabela de Souza Gusmão no $3^{\circ}$ Simpósio Aprender com Cultura e Extensão, realizado em Ribeirão Preto.

\section{Objetivos}

A região da Estância Turística de Piraju (SP) é um dos pontos turísticos mais interessantes da região sudeste brasileira, por causa de seus recursos naturais, culturais e, mais recentemente, os esportivos. O desenvolvimento da canoagem no rio Paranapanema trouxe uma mudança no comportamento dos moradores, sobretudo os jovens, que passaram a enxergar a modalidade para além do lazer, como uma forma de ascensão social, já que muitos atletas locais se destacaram no cenário internacional. Com isso, os principais objetivos deste trabalho foram os de divulgar os valores olímpicos e de auxiliar o desenvolvimento das modalidades olímpicas pelo jornalismo.

\section{Material, Métodos e Ações Desenvolvidas}

As ações desenvolvidas foram conduzidas pela produção de materiais jornalísticos sobre o esporte olímpico no Brasil. Para baratear o custo, foi construído um site junto ao Departamento de Jornalismo e Editoração da USP. Este espaço foi fundamental para a inserção de informações (impressas e em audiovisual) sobre a canoagem em Piraju. Desta forma, foi possível construir um método simples para a inserção dos dados on-line.

\section{Resultados}

a) Realização de trabalhos de divulgação esportiva em plataforma multimídia, com a bolsista sendo estimulada pelo contato com os valores olímpicos e as técnicas em jornalismo 
esportivo; b) Construção de um site ${ }^{* *}$ destinado ao desenvolvimento da canoagem, pela inserção de dados captados no local pela bolsista, disponibilizados por colaboradores (principalmente pela canoísta e professora Milene Wolf) ou coletados em outras fontes.

\title{
Conclusões
}

Foram estimulados os valores olímpicos, como a excelência, a amizade e o respeito, por meio da divulgação do trabalho realizado em Piraju (SP). Permitiu-se à bolsista, aluna do curso de Esporte da USP, o contato com esportistas e com o jornalismo. Foi possível, ainda, disponibilizar um espaço para a divulgação de uma modalidade.

\section{Considerações Finais}

Com a proximidade das Olimpíadas do Rio de Janeiro em 2016, a experiência de Piraju é um exemplo para que o legado do evento no Brasil deixe marcas para o futuro. Este projeto é uma proposta jornalística a ser utilizada para o desenvolvimento do esporte olímpico no Brasil. Além deste projeto, a USP está presente no município com a manutenção do Centro de Arqueologia Ambiental do Museu de Arqueologia e Etnologia (MAE).

\section{PROJETOS DE CULTURA E EXTENSÃO EM JORNALISMO}

\author{
ORAÇÃO DO MILHO
}

Sou a planta humilde dos quintais pequenos e das lavouras pobres.

Meu grão, perdido por acaso, nasce e cresce na terra descuidada.

Ponho folhas e haste e se me ajudares, Senhor, mesmo planta de acaso, solitária, dou espigas e devolvo em muitos grãos, o grão perdido inicial, salvo por milagre, que a terra fecundou.

Sou a planta primária da lavoura.

Não me pertence a hierarquia tradicional do trigo.

E de mim, não se faz o pão alvo, universal.

O Justo não me consagrou Pão da Vida, nem lugar me foi dado nos altares.

Sou apenas o alimento forte e substancial dos que trabalham a terra, onde não vinga o trigo nobre.

Sou de origem obscura e de ascendência pobre.

Alimento de rústicos e animais do jugo.

Fui o angú pesado e constante do escravo na exaustão do eito.

Sou a broa grosseira e modesta do pequeno sitiante.

Sou a farinha econômica do proletário.

Sou a polenta do imigrante e a miga dos que começam a vida em terra estranha.

Sou apenas a fartura generosa e despreocupada dos paióis.

Sou o cocho abastecido donde rumina o gado

** www.eca.usp.br/cje/canoagempiraju 
Sou o canto festivo dos galos na glória do dia que amanhece.

Sou o cacarejo alegre das poedeiras à volta dos seus ninhos.

Sou a pobreza vegetal, agradecida a Vós, Senhor, que me fizeste necessária e humilde

SOU O MILHO

$[4]$

Levar o conhecimento para além dos muros das universidades é um dos desafios dos docentes e pesquisadores da Universidade de São Paulo. Um compromisso assumido em conjunto com as aulas, pesquisas, publicações e demais atributos da rotina acadêmica. São propostas de um grupo de profissionais dispostos a oferecer um pouco de seu tempo à comunidade e à construção de um país.

Boa parte dos projetos de cultura e extensão visa ampliar o horizonte dos alunos que, em muitos casos, traduzem a academia como um universo distante e fora da realidade. Desta forma, a possibilidade de convívio com as pessoas (e, por conseguinte, diminuir diferenças) é também uma maneira de quebrar um certo preconceito existente para com a universidade no Brasil.

A área da saúde talvez seja um dos espaços de destaque pela apresentação de propostas que permitem a aplicabilidade direta de conhecimentos junto ao cidadão. Assim, o Hospital Universitário e o Hospital das Clínicas da Faculdade de Medicina da USP conseguem atingir o patamar de excelência pela relação entre o ensino, a pesquisa e a extensão. Muitas propostas tentam popularizar o saber, demonstrando que é possível conhecer e aplicar metodologias para finalidades antes desconhecidas.

Se o lugar do repórter é na rua, projetos de cultura e extensão são intrínsecos ao jornalismo que, geralmente, segue uma linha de serviços reforçada pela tentativa de abertura das mídias, transformando os meios de comunicação (jornal, rádio, televisão, internet e outras mídias) em espaços democráticos, voltados ao debate em torno das condições sociais. Para isso, os repórteres convivem com as situações, dos acontecimentos às personagens. O jornalista necessita "saber das coisas", como diz o ditado popular, justamente para facilitar a interpretação do público diante do desconhecido.

Além da divulgação, reforçar a integração entre a população e a comunidade acadêmica está entre os principais objetivos do trabalho de extensão em jornalismo. Os projetos revelam, assim, a possibilidade de aprendizado contínuo promovido pela troca de experiências. A reportagem é o exemplo mais visível deste comportamento, com o jornalista a conviver com uma realidade antes desconhecida. Torna-se possível compartilhar e, ao mesmo tempo, encontrar caminhos.

\section{JORNALISMO ESPORTIVO}

O olimpismo, na percepção do Comitê Olímpico Internacional (COI), de acordo com a Carta Olímpica, é entendido como a base filosófica que envolve o movimento olímpico e exalta as qualidades do corpo, a vontade e o espírito, associando-se ao esporte, à educação e à cultura. O Olimpismo é considerado a própria filosofia do esporte, contribuindo para um estilo de vida das pessoas, pela: alegria do esforço físico, valor educativo do bom exemplo e respeito pelos princípios éticos universais [12]. 
A especialização em esportes nem sempre é compreendida pelos editores das redações dos principais periódicos. Muitos jornalistas colocam a notícia apenas como um meio de promoção de eventos e é por isso que os noticiários são preenchidos, em sua maioria, por anúncios e resultados das principais competições (aquelas com patrocinadores e de interesse das emissoras, em particular, a televisão). O futebol, o tênis, o basquete, o vôlei, as lutas são alguns dos esportes que ficam sempre em evidência nos principais meios de comunicação.

As modalidades com menos recursos e organização, assim como as atividades físicas e esportivas, ficam relegadas aos breves espaços, geralmente cedidos quando acontece algum fato inédito (como uma conquista, contusão ou punição) ou mesmo durante o período de campeonatos mundiais, como a Copa do Mundo de Futebol, os Jogos Olímpicos ou Pan-Americanos.

A mudança desse quadro contribuirá para o desenvolvimento do esporte em países como o Brasil; e a semente já está sendo implantada nas principais universidades, como a USP. O Departamento de Jornalismo e Editoração da Escola de Comunicações e Artes (ECA-USP) oferece, há três anos, a disciplina optativa Jornalismo Esportivo: a prática além do futebol, que recebe alunos dos mais variados cursos, além dos inscritos no programa Universidade Aberta à Terceira Idade. A intenção é apresentar algumas ferramentas do jornalismo que possam ser utilizadas nas mais diversas áreas do conhecimento. A produção de crônicas, artigos, entrevistas, reportagens e blogs compõem o quadro de uma cobertura esportiva baseada na ética, na interatividade e nos princípios do olimpismo.

A cada dia aumenta o interesse dos alunos de graduação e de pós-graduação, além de professores e funcionários, em desenvolver trabalhos sobre temas relacionados ao esporte. Destaque para o fortalecimento da pesquisa como caminho de reflexão e aperfeiçoamento do jornalista, tanto no meio acadêmico como no profissional. Neste âmbito, o Programa de Pós-Graduação em Ciências da Comunicação da ECA-USP oferece a disciplina A Pauta Esportiva e Olímpica: reflexões entre Jornalismo e Turismo como um espaço para a análise de temas de impacto diante da comunicação, do urbanismo e do lazer. O interesse é possibilitar um aumento do número de projetos de mestrado e doutorado com temas relacionados ao esporte, ao olimpismo e suas vertentes.

A relevância social é fundamental aos projetos acadêmicos em jornalismo e, por isso, tornam-se incompletos sem propostas diante da cultura e da extensão. A organização de eventos, cursos, além da distribuição do material produzido, são reflexos do trabalho de ensino e pesquisa e integram o processo de divulgação da ciência e da tecnologia. Além de diversos encontros, o Departamento de Jornalismo e Editoração da ECA-USP oferece oficinas e cursos gratuitos destinados à iniciação e ao aperfeiçoamento na área, com destaque para os cursos organizados por iniciativa do Prof. Dr. José Coelho Sobrinho, como o de Jornalismo e Políticas Públicas Sociais, em parceria com a Agência de Notícias dos Direitos da Infância (ANDI) e a Rede ANDI Brasil, e o projeto Redigir***, uma iniciativa cidadã dos alunos do curso de Jornalismo, por meio

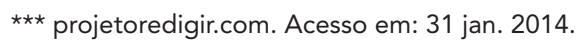


do ensino da língua portuguesa. Diante do esporte, torna-se fundamental o trabalho do Grupo de Pesquisa em Jornalismo Popular e Alternativo (ALTERJOR), que oferta oficinas com temas relacionados a trabalhos independentes que podem ser realizados fora da chamada grande mídia, entre elas, a de Jornalismo Olímpico e da Cobertura Jornalística sobre Copa do Mundo, como a de 2014, a ser realizada no Brasil.

\section{NOTÍCIA ESPORTIVA}

A função da notícia é orientar o homem e a sociedade num mundo real. Na medida em que consegue, tende a preservar a sanidade do indivíduo e a permanência da sociedade [11].

A construção da notícia é uma tarefa árdua para o jornalista, pelo constante contato com as situações que, muitas vezes, são delicadas e exigem um certo rigor em termos de apuração. No jornalismo esportivo, as dificuldades são permanentes em termos de estrutura e, entre elas, está a divulgação. Há pouco interesse em modalidades pouco conhecidas ou praticadas, que aparecem somente em momentos específicos, como na ocasião dos Jogos Olímpicos.

O momento agora é delicado, porque as Olimpíadas serão realizadas no Brasil, com sede na cidade do Rio de Janeiro, em 2016. A pauta esportiva está concentrada, atualmente, no desempenho dos atletas e na cobrança dos gastos para com o evento. Diante do legado, fica a esperança de melhores condições aos esportistas, assim como benefícios à população em relação à infraestrutura, no caso dos transportes, educação, praças esportivas e assim por diante.

A notícia esportiva traz, neste momento, uma discussão sobre a própria função do jornalista e, por conseguinte, dos comunicadores: seria mais uma oportunidade de mudança da própria sociedade? Uma forma de contestação por meio do esporte, não somente como crítica para com os eventos aqui realizados, como a Copa do Mundo e os Jogos Olímpicos, mas uma maneira de repensar o próprio modo de vida dos brasileiros.

Trata-se de um momento de solidariedade, de dar um tempo na vida acelerada, de se preocupar consigo e com o próximo, olhando nos olhos de quem precisa. Surge a oportunidade de aproveitar as calçadas, um pedaço das ruas, o rio, o mato, o mar, as areias, as quadras, os campos e todos os locais onde exista a possibilidade de cultuar o corpo e mente.

O compromisso do jornalismo é para com as pessoas - o de mostrar onde realidades estão sendo construídas, no meio do esforço e das dificuldades. Para isso, surgem as reportagens, as páginas na internet, revelando que o esporte está tão próximo quanto o estudo e o trabalho. Um movimento que nos acelera para o bem.

\section{CONSIDERAÇÕES FINAIS}

O jornalismo é uma obra de criação que tem que ter a pretensão de transformar. $\mathrm{O}$ nosso protagonismo é o protagonismo dos narradores, mas a nossa pretensão tem que ser essa, a pretensão de transformar. As pessoas são a razão de ser do nosso trabalho, 
por mais que os sujeitos sociais sejam instituições. Essa institucionalização é irreversível e boa, pois é pela instituição que o mundo se tornou falante. Entretanto, nós temos que pensar nas pessoas. A transformação é importante na medida em que elimina as exclusões, as diferenças e as desigualdades; na medida em que ajuda as pessoas a serem felizes e a entenderem o mundo e o seu próprio papel no mundo. Então é para as pessoas que a gente trabalha, não é para as instituições [2].

O interesse em projetos de cultura e extensão, particularmente do servidor público ligado à educação, é reforçado pelo princípio da solidariedade, uma fórmula de auxílio à comunidade, como meio de facilitar o acesso ao desconhecido. No jornalismo, é possível diminuir a distância pela notícia, independentemente da mídia. Do analógico ao digital, o fundamental é a informação para todos.

O curso de graduação em Comunicação Social, com habilitação em Jornalismo, da Escola de Comunicações e Artes (ECA-USP) segue o princípio da Universidade Aberta, apresentando diversas atividades e serviços à comunidade. Neste âmbito, além dos já citados, incluem-se ainda as distribuições de jornais impressos (Jornal do Campus, Notícias do Jardim São Remo, suplemento Claro!), exposições fotográficas (Espaço Milton Santos e Espaço D’Ávila), programas de rádio (Universidade 93,7 da Rádio USP), periódicos on-line (Agência Universitária de Notícias (AUN), Portal do CJE, Revista Babel, Revista Anagrama, livros, entre outros), vídeodocumentários e assim por diante. A ideia é que cada docente tenha um produto de sua responsabilidade e que, pelo menos uma vez por ano, ofereça uma atividade de cultura e extensão, sempre gratuitas e abertas ao público externo. Logo, os resultados do projeto sobre a cidade olímpica de Piraju são frutos do contexto do Departamento de Jornalismo e Editoração.

No âmbito comunitário, tentamos mostrar a luta de uma cidade para manter o meio ambiente preservado e, por conseguinte, a qualidade de vida da população. Lá, as pessoas nadam, praticam canoagem e outras modalidades no rio Paranapanema. Crianças e adultos se unem por meio do esporte e do lazer, da mesma forma como os ciclistas da Avenida Paulista aos domingos.

\section{REFERÊNCIAS}

[1] CERVEIRA FILHO, J. L. F.; MALULY, L. V. B. Comunicação, Esporte, Turismo e Meio Ambiente: como a canoagem transformou Piraju (SP) em Cidade Olímpica. In: Organicom (USP) n. 15, $2^{\circ}$ semestre de 2011.

[2] CHAPARRO, M. C. C. Transcrição da Palestra promovida em o6/o5/2006 na Escola de Comunicações e Artes. Disponível em: <http://www.obore. com.br/cms-arquivo/Transcri\% $\mathrm{C}_{3} \% \mathrm{~A}_{7} \%_{3} \mathrm{C}_{3} \mathrm{~A}_{30} \% 20$ Manuel\%20Carlos\%20 Chaparro.pdf $>$. Acesso em: 29 jan. 2014.

[3] COMITÊ OLÍMPICO BRASILEIRO. Olimpismo - suas origens e ideais. Rio de Janeiro: COB, 2010.

[4] CORAlina, Cora. Oração do Milho. In: Poemas dos Becos de Goiá e Estórias Mais. São Paulo: Global Editora, 1985. Disponível em: <http://leonardoboff. wordpress.com/2012/11/o4/elogio-do-milho/>. Acesso em: 25 jan. 2014. 
[5] DA COSTA, L. \& HATZIDAKIS. Estudos olímpicos 2011 - Coletânea de Textos. São Paulo: UNIBAN, 2001.

[6] GURGEL, Anderson. Futebol S/A - a economia em campo. São Paulo: Saraiva, 2009.

[7] MARQUES, José Carlos. Comunicação e esporte - diálogos possíveis. São Paulo: Artcolor, 2007.

[8] José Carlos; CARVALHO TOLEDO, Vera Regina \& CARVALHO, Sérgio. (Orgs.) Comunicação e esporte - tendências. Santa Maria: Pallotti, 2005.

[9] MARTINS, Isildinha. A comunicação nas organizações desportivas no Brasil - profissionais e instrumentos. (Tese de doutorado) São Bernardo do Campo: Umesp, 2006.

[10] MORAES, Vinícius. Extensão. In: O Caminho para a distância. Rio de Janeiro: SchmidtEditora, 1933. Disponível em: <http://www.viniciusdemoraes.com.br/ pt-br/poesia/livros/o-caminho-para-distancia>. Acesso em: 04 fev. de 2014.

[11] PARK, R. E. A notícia como forma de conhecimento. In: STEINBERG, C. S (Org.). Meios de Comunicação de Massa. São Paulo: Cultrix, 1966, p. 169-185.

[12] TUBINO, Manoel. O que é olimpismo. Coleção Primeiros Passos. São Paulo: Brasiliense, 2007.

[13] VIANA, Oswaldinho. Brasilinha. Faixa 5. In: VIANA, Oswaldinho. São Sebastião do Tijuco Preto (CD). São Paulo: Carambola, 1996. CD (ca. 57'11”) digital, estéreo.

[14] VIGU, Paulo. Água Boa (essa cidade é o cais). Faixa 1. In: VIGU, Paulo. Piraju: Peixe Amarelo (o Dourado Brasileiro) (CD). Piraju: MCK, 2002. CD (ca. o1ho6'49") digital, estéreo.

\section{SITES}

http://www.cob.org.br/home/home.asp/

http://cbca.org.br/

http://www.canoagem.org.br

http://www.estanciadepiraju.com.br

http://www.eca.usp.br/cje/canoagempiraju

http://projetoredigir.com/

\section{COLABORADORAS}

Sandra do Val (Revisão)

Daniela Ades (Tradução)

LUCIANO VICTOR BARROS MALULY doutor em Ciências da Comunicação e docente da Escola de Comunicações e Artes da Universidade de São Paulo (ECA-USP) - e-mail: lumaluly@usp.br 